\title{
Multidrug Resistance Patterns and Multiple Antibiotic Resistance Index of Salmonella species Isolated from Waste Dumps in Zaria Metropolis, Nigeria
}

\section{*NYANDJOU, YMC; YAKUBU, SE; ABDULLAHI, IO; MACHIDO, DA}

\author{
Department of Microbiology, Ahmadu Bello University, Zaria, Nigeria
}

*Corresponding Author Email: marieyomi2016@mail.com

\begin{abstract}
Several items containing residual antimicrobial agents are disposed of in dumpsites, placing a pressure on the microbial flora and a potential for development of resistance in these microorganisms. Multidrug resistance patterns and multiple antibiotic resistance index of Salmonella spp. isolated from waste dumps in Zaria Metropolis were thus assayed in this study using one hundred and twelve (112) soil samples collected from four waste dumpsites located thus assayed in this study using one hundred and twelve (112) soil samples collected from four waste dumpsites located
in Sabon-Gari, Samaru, Tudun-Wada and Zaria City. Salmonella spp. were isolated by culture methods on selective media and characterized using a series of biochemical tests. The isolates were confirmed using microgen identification kits. Results were statistically analysed using percentages. The antibiotic resistance patterns were determined, using the disc-diffusion method. Ten antibiotics belonging to eight different classes, namely B-lactams, aminoglycosides,

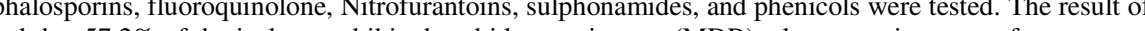
the study revealed that $57.2 \%$ of the isolates exhibited multidrug resistance (MDR) taken as resistance to four or more

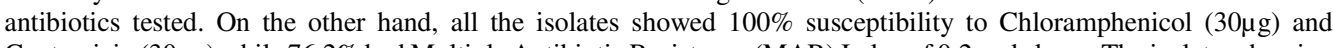

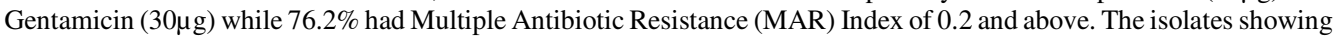
resistance to the highest number of antibiotics were obtained from refuse dumpsites in Zaria City while an isolate from Sabon-Gari was found to be resistant to six antibiotics. These results could be indicative of possible disposal of these drug residues in the waste dump locations making them hot spots for development of resistance.
\end{abstract}

\section{DOI: https://dx.doi.org/10.4314/jasem.v23i1.6}

Copyright: Copyright (ㅇ 2019 Nyandjou et al. This is an open access article distributed under the Creative Commons Attribution License (CCL), which permits unrestricted use, distribution, and reproduction in any medium, provided the original work is properly cited.

Dates: Received: 24 October 2018; Revised: 02 January 2019; Accepted 17 January 2019

Keywords: Salmonella spp., Waste Dumps, Resistance Pattern, MAR Index, Zaria Metropolis.

Antibiotics are present in different environments as a result of their use in human and veterinary medicine. Inappropriate and irrational uses of antimicrobial medicines provide favourable conditions for resistant microorganisms to emerge, spread and persist (WHO, 2011). Antimicrobial resistance (AMR) is considered one of the most important global threats to human health in the $21^{\text {st }}$ century (Liu et al., 2016). Increased outbreaks of enteric illnesses have invariably led to increased use of antibiotics for managing infections. AMR threatens the effective prevention and treatment of an ever increasing range of infections caused by bacteria, parasites, viruses and fungi; a post antibiotic era, in which common infections and minor injuries can kill and is a real possibility in the $21^{\text {st }}$ century. Salmonella is the most common causative agent of a wide range of human diseases such as enteric fever, gastroenteritis, bacteraemia and other complications of non typhoidal salmonellosis. The Salmonellae are constantly found in environmental samples because they are excreted by humans, pets, farm animals and wild life (Nazzal et al., 2012). The presence of Salmonella spp. and other bacteria genera such as Pseudomonas, Staphylococcus, Vibrio, Neisseria,
Escherichia coli, Shigella, Bacillus and Klebsiella in refuse dumps is indicative of possibly serious public health risk to waste handlers, scavengers and people living in the vicinity (Awisan et al., 2011). Increase antibacterial drug resistance in Salmonella species has been a serious problem for public health worldwide and are of concern (WHO, 2014). The concentrations currently found in different environments and concentrations representing action limits used in environmental risk assessment may be high enough to exert a significant selective pressure on clinically relevant bacteria (Liu et al., 2016). Multidrug resistance (MDR) is a common problem that hurdles chemotherapy. To overcome this problem, it is important to identify the multidrug resistance pattern of an isolate. An attempt was made in this study to isolate Salmonella spp. from refuse dumps, and to determine their MDR pattern by subjecting the isolates to antibiotic susceptibility study.

\section{MATERIALS AND METHODS}

Study area: The survey was conducted in parts of Zaria Metropolis, Nigeria. The locations were SabonGari, Samaru, Tudun-Wada and Zaria City. Zaria 
Metropolis is located on the high plains of Northern Nigeria, on latitudes $11^{\circ} 07^{\prime} \mathrm{N}$ to $11^{\circ} 51^{\prime} \mathrm{N}$ and longitudes $7^{\circ} 43^{\prime} \mathrm{E}$ to $7^{\circ} 45^{\prime} \mathrm{E}$ (Uba et al., 2013). These are semi-urban with a high population density with the attendant generation of wastes. These wastes are seen disposed within the community owing to the poor waste disposal systems posing a risk of transmission of various disease agents.

Sample Collection: A total of 112 soil samples were collected from 4 dumpsites locations in Samaru (28), Sabon-Gari (28), Tudun-Wada (28) and Zaria City (28). At each sampling site, surface debris was removed and soil was dug to a depth of $15 \mathrm{~cm}$ using a hand trowel (Isirima et al., 2005). Soil was then scooped into a clean low density polythene bag and transported in cool boxes to the Bacteriology Laboratory in the Department of Microbiology, Ahmadu Bello University, Zaria for analysis. Samples were stored at $4^{\circ} \mathrm{C}$ if not analysed immediately.

Identification and Characterization of Salmonella spp: Briefly, $25 \mathrm{~g}$ of each soil sample was suspended in $225 \mathrm{ml}$ sterile distilled water, and mixed using a sterilized glass rod. Then $1 \mathrm{ml}$ of the resultant solution was enriched in $9 \mathrm{ml}$ of sterile Selenite cysteine broth (Difco) in sterile duplicate McCartney bottles and incubated for $18-24 \mathrm{hrs}$ at $37^{\circ} \mathrm{C}$ for 24 hours. Aseptically, inoculations were made from the overnight cultures on prepared sterile plates of Salmonella Shigella Agar (SSA) (Oxoid). All inoculated plates were incubated aerobically at $37^{\circ} \mathrm{C}$ for 48 hours for isolation of Salmonellae (Cheesebrough, 2006). Discreet colonies showing transparent colonies with dark centres were picked as presumptive Salmonella spp. The presumptive isolates were subjected to routine IMViC tests (Indole, Methyl red, Voges Proskaur, citrate utilization tests), Sugar fermentation in Triple Sugar Iron (TSI) agar, Hydrogen sulphide formation test among other tests. Isolates giving atypical responses for any of the above named tests were examined further using Microgen ${ }^{\mathrm{TM}}$ Gram negative Identification A system. The data obtained by the Microgen GN-ID A microwell strip was designed to generate a 4 digit octal code which was used to interpret the result from the Micogen Identification System Software (Nyandjou et al., 2017).

Antibiotic Susceptibility Testing: Susceptibility of Salmonella spp. to ten antibiotics was determined using the disc-diffusion method as recommended by Clinical Laboratory Institute Standards (CLSI, 2014). The bacterial isolates were grown for 18 hours on nutrient agar at $37^{\circ} \mathrm{C}$. They were suspended in $2 \mathrm{ml}$ normal saline and turbidity adjusted to match
McFarland Optical Standard 0.5 (equivalent to $1.5 \mathrm{x}$ $\left.10^{8} \mathrm{cfu} / \mathrm{ml}\right)$. Bacterial suspensions $(0.1 \mathrm{ml})$ were dispensed on the surface of sterile Mueller-Hinton agar (Oxoid, UK) plate and spread evenly using a sterile spreader. This was allowed to dry for $5 \mathrm{~min}$ and antibiotic discs were placed on the surface of the agar plates and incubated aerobically at $37^{\circ} \mathrm{C}$ for 18 hours. The susceptibility patterns of the isolates to the different antibiotics were noted as Sensitive (S), Intermediate (I) or resistant $(\mathrm{R})$ following the standard of the CLSI (CLSI, 2014). The following antibiotics (single discs, Oxoid Ltd., Basingstolke, Hamphire, England) were tested: Ampicillin (10 $\mathrm{g})$, Amoxycillin-clavulanic acid (30 $\mu \mathrm{g})$, Chloramphemicol (30 $\mu \mathrm{g}), \quad$ Ceftriaxone $(30 \mu \mathrm{g})$, Ciprofloxacin $(10 \mu \mathrm{g})$, Gentamicin $(30 \mu \mathrm{g})$, Ofloxacin $(10 \mu \mathrm{g})$, Tetracycline $(30 \mu \mathrm{g})$, Nitrofurantoin $(30 \mu \mathrm{g})$ and Sulphamethozazole/Trimethoprim $(25 \mu \mathrm{g})$ (CLSI, 2014). Isolates that were observed to be resistant to at least four different antibiotics were classified as being multidrug resistant (Ezekiel et al., 2011).

Determination of Multiple Antibiotic Resistance (MAR) Index: The multiple antibiotic resistance index $\mathrm{a} / \mathrm{b}$ was calculated, where a represents the number of antibiotics to which the isolates were resistant and $b$ represents the total number of antibiotics to which the isolate was exposed (Mishra et al., 2013).

\section{RESULTS AND DISCUSSION}

Salmonella spp. were obtained from soil samples of all locations and from all the dumpsites that were sampled (Tables 1). The antibiotic susceptibility pattern of 21 isolates of Salmonella spp. to ten commonly used antibiotics is presented in Table 2. The result indicated that $90 \%$ Salmonella spp. isolates were susceptible to Nitrofurantoin $(30 \mu \mathrm{g}), 100 \%$ to Gentamicin $(30 \mu \mathrm{g})$

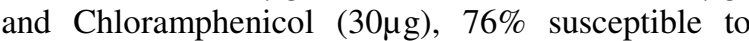
Ciprofloxacin $(10 \mu \mathrm{g}), 62 \%$ to Ofloxacin $(10 \mu \mathrm{g})$ and $57 \%$ to Ceftriaxone $(30 \mu \mathrm{g})$ (Table 3$)$. On the other hand, $90 \%$ were resistant to Ampicillin, followed by Tetracycline $(81 \%)$, Amoxycillin-clavulanic acid (71\%), and Sulphamethoxazole-trimethoprim (52\%).

The antibiotic resistant pattern of the Salmonella isolates is presented in Table 3. The results showed that the isolates produced 10 phenotypic resistance profiles and were resistant to 2-7 antibiotics. The isolates with the highest multidrug resistance were obtained from Zaria city. One isolate obtained from Sabon-Gari was found to be resistant to six antibiotics. Most of the resistant isolates in this study showed the Amp-Aml-Cef-Sxt-Te -resistance pattern. These antibiotics belong to the $\beta$-lactams, Sulfonamides and Tetracycline classes of antibiotics. 


\begin{tabular}{llccl}
\multicolumn{5}{l}{ Table 1: Distribution of Salmonella spp. isolated from waste dumpsites in various locations } \\
\hline $\begin{array}{l}\text { Sampling } \\
\text { Location }\end{array}$ & Dump Location & $\begin{array}{l}\text { Number of } \\
\text { Sample } \\
\text { Collected }\end{array}$ & $\begin{array}{l}\text { Salmonella } \\
\text { spp. N }(\%)\end{array}$ & $\begin{array}{l}\text { Number of } \\
\text { isolates/location } \\
\text { N (\%) }\end{array}$ \\
\hline Sabon-Gari & Army children school & 7 & $1(14.3)$ & $6(21.4)$ \\
& Chikaji & 7 & $2(28.6)$ & \\
& Independent cinema & 7 & $1(14.3)$ & \\
& Rail way Yan Katako & 7 & $2(28.6)$ & \\
Samaru & Hayin-Dogo & 7 & $2(28.6)$ & $4(14.3)$ \\
& Kwangila & 7 & $1(14.3)$ & \\
& Danra Estate & 7 & $0(0.0)$ & \\
& Palladan & 7 & $1(14.3)$ & \\
Tudun-Wada & Agolo & 7 & $3(42.9)$ & $7(25.0)$ \\
& Kwarin & 7 & $2(28.6)$ & \\
& PZ & 7 & $0(0.0)$ & \\
& Total Filling Station & 7 & $2(28.6)$ & \\
Zaria City & Al-Hudahuda & 7 & $2(28.6)$ & $11(39.3)$ \\
& Dan-Gama & 7 & $3(42.9)$ & \\
& Kusfa-Zaria & 7 & $4(57.1)$ & \\
& Limancikwana & 7 & $2(28.6)$ & \\
\hline & & & &
\end{tabular}

Table 2: Antimicrobial Susceptibility Patterns of Salmonella spp. Isolates from Waste Dump Samples

\begin{tabular}{lllll}
\hline & \multicolumn{4}{c}{ Salmonella spp. (N=21) } \\
\cline { 2 - 5 } Antibiotics Tested & Symbol $(\boldsymbol{\mu g})$ & $\mathbf{R}(\%)$ & $\mathbf{I}(\%)$ & S (\%) \\
Ampicillin & AMP $(10)$ & $19(90.5)$ & $1(4.8)$ & $1(4.8)$ \\
Amoxycillin-clavulanic acid & AMC (30) & $15(71.4)$ & $4(19.1)$ & $2(9.5)$ \\
Chloramphenicol & CHL $(30)$ & $0(0.0)$ & $0(0.0)$ & $21(100)$ \\
Ceftriaxone & CEF (30) & $8(38.1)$ & $1(4.8)$ & $12(57.1)$ \\
Ciprofloxacin & CIP $(10)$ & $2(9.5)$ & $3(14.3)$ & $16(76.2)$ \\
Gentamicin & CN (30) & $0(0.0)$ & $0(0.0)$ & $21(100)$ \\
Nitrofurantoin & F (30) & $2(9.5)$ & $0(0.0)$ & $19(90.4)$ \\
Ofloxacin & OFX (10) & $4(19.0)$ & $4(19.0)$ & $13(62.0)$ \\
Sulphamethoxazole/trimethoprim & SXT (25) & $11(52.4)$ & $1(4.8)$ & $9(42.9)$ \\
Tetracycline & TE (30) & $17(81.0)$ & $0(0.0)$ & $4(19.0)$ \\
\hline \multicolumn{2}{c}{ Key: N-Number of isolates tested, - - Resistant, I-Intermediate, S-Susceptible }
\end{tabular}
Key: $N$-Number of isolates tested, R-Resistant, I-Intermediate, S-Susceptible

Table 3: Antibiotic Resistance Patterns of Salmonella spp. Isolates

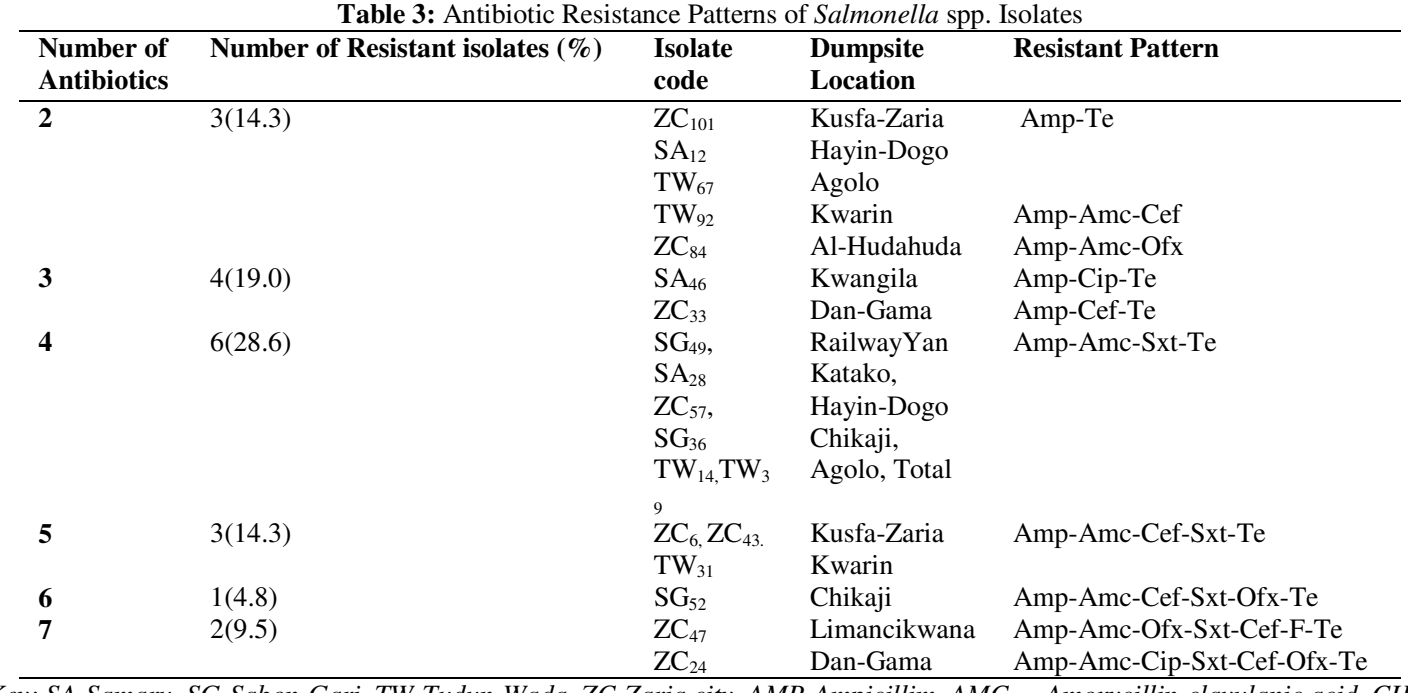

Key: SA-Samaru, SG-Sabon-Gari, TW-Tudun-Wada, ZC-Zaria city, AMP-Ampicillim, AMC-Amoxycillin-clavulanic acid, CHLChloramphenicol, CIP-Ciprofloxacin, CEF-Ceftriazone, GN-Gentamicin, SXT-Sulphamethoxazole/trimrthoprim, F-Nitrofurantoin, TETetracycline

Fifty seven $(57 \%)$ of the isolates tested were multidrug resistant (MDR). Multidrug resistance was taken as resistance of isolate to at list four different antibiotics (Ezekiel et al., 2011). Multiple resistance was 
observed with $9.5 \%, 28.6 \%, 4.8 \%$ and $14.3 \%$ resistant to 7, 4, 6 and 5 antibiotics respectively (Figure 1). The occurrence of Multiple Antibiotics Resistance Index (MARI) ranged from $0.2-0.7$. Isolates with 0.4 had the highest occurrence of $28.6 \%$, followed by isolates with $0.3(19.0 \%), \quad 0.5(14.3 \%), \quad 0.2(14.3 \%)$ and $0.7(9.5 \%)$. Isolates with 0.6 MARI had the least occurrence of $4.8 \%$ (Figure 2). Isolation of Salmonella spp. from refuse dumpsites showed that waste management is generally poor in the locations that were sampled. Salmonella is the most common causative agent of a wide range of human diseases. The Salmonellae are constantly found in environmental samples because they are excreted by humans, pets, farm animals and wild life. Their presence in waste directly confirms the presence of faecal wastes at various dumpsites since it was common practice to dump human excreta in the sites which could also be used as latrines at night. The organisms have also been isolated by other researchers who worked with waste dumps in other parts of the country like (Ikpeme et al., 2011; Odeyemi et al., 2011; Adekanle et al., 2014). The variation in the susceptibility and resistance level of the Salmonella isolates to different classes of antibiotics in this study could be due to differences in strains from location to location thus the rate of resistance to antibiotics varies among them. High incidence resistance was evident against Ampicillin (90.5\%), Amoxycillin-clavulanic acid $(71.4 \%)$ and Tetracycline $(81 \%)$. Resistance of the Salmonella isolates to various antibiotics has been demonstrated in previous studies (Boyen et al., 2008; Duru et al., 2014; Titilawo, 2015). The marked resistance of species of Salmonella to $\beta$-lactams and Tetracycline classes of antibiotics as shown in the present study agrees with the findings of Ash et al. (2002) and Gregory et al. (2013) working on rivers in the United States. Similarities in antibiograms among isolates from both environmental sources indicate a possible infiltration of pathogens from dumpsite soils to water sources. The high resistance observed to Tetracycline may be attributed to it being the most commonly available antibiotic used as growth promoter and routine chemoprophylaxis among livestock in Nigeria (Olatoye, 2010). This is worrisome considering the fact that Tetracycline is a first line drug in Nigeria, and as in most developing countries, people with gastrointestinal infections readily purchase it across the counter for selfmedication (Chigor et al., 2010). Results of several studies have also revealed bacterial resistance to the penicillin family (Ampicillin and Amoxicillinclavulanic acid in this study) [Ikpeme et al., 2011; Odeyemi, 2012; Adekanle et al., 2014; Nyandjou et al., 2017]. These could be because these antimicrobial agents are inexpensive and affordable. The inexpensive drugs in developing countries are widely available across the counter without prescription from authorised health institutions and pharmacies, as well as from unauthorised patent medicine shop and other distributors (Sharma and Rai, 2012). The observed high resistance of the isolates to some of the antibiotics in this study is not surprising as factors that could promote or encourage development of antibiotic resistance such as non-adherence to treatment strategies, sub-standard drugs, over the-counter sale of potent antibiotics and self-medication are present in developing countries including Nigeria. Over use/miss-use and the use of antibiotics at low concentration is a potentially dangerous practice that can encourage the production of antibiotic resistant organisms.

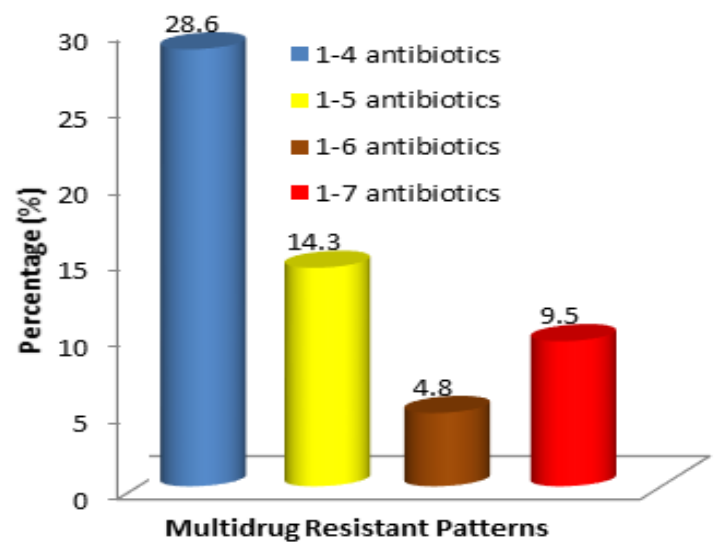

Fig 1: Percentage Multidrug Resistance of Salmonella spp. Isolates

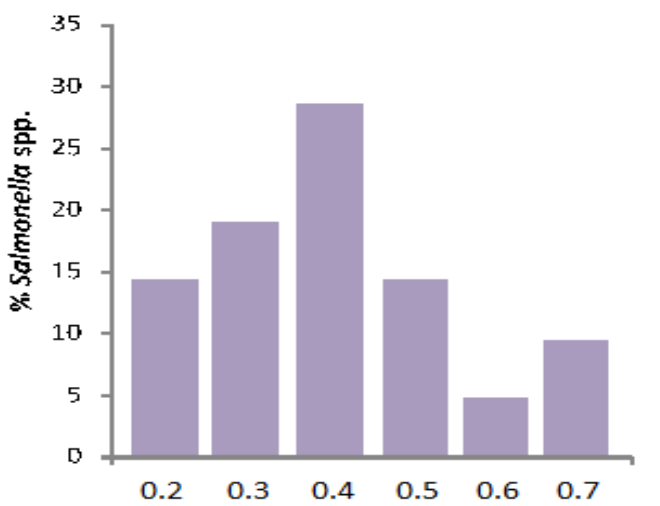

Multiple Antibiotic Resistance (MAR) Index

Fig 2: Percentage Salmonella spp. and their Multiple Antibiotic Resistance Indices

When people use sub-therapeutic doses of antibiotics, as obtained when the dosage for the drugs are not strictly adhered to, highly resistant strains of the organisms are selected sequentially. Poor quality drugs can provide sub-inhibitory selective pressure, of which neither the patient nor the prescriber may be aware. There have been numerous reports of substandard drugs in Nigeria. These reports describe drug 
preparations containing between $0-80 \%$ of the stated label claim. Some of them contain such low concentrations that they can only be considered counterfeit, meaning that they were deliberately manufactured with low or no active drug content. Others may have complied with pharmacopoeia standards at some time but have, in the course of distribution and display, been degraded by heat and humidity (Okeke and Sosa, 2003).

The isolates were susceptible to Chloramphenicol, Gentamicin followed by Ciprofloxacine and ceftriazone. This agrees with the work of Tesfaw et al. ( 2013), Jasil et al. (2016) who reported high susceptibility of Salmonella spp. isolates to fluoroquinolone and third-generation cephalosporin (Ciprofloxacine and Ceftriazone in this study). High susceptibility levels to the newer, more valuable antimicrobial compounds, such as phenicols, aminoglycosides, as well as fluoroquinolones and third-generation cephalosporin could yield good therapeutic results in treating infections caused by MDR Salmonella spp. and probably Enterobacteriaceae in general. Multidrug resistance has become a common feature of many microorganisms especially the human pathogens. Data obtained in this study showed higher percentage MDR $(57.2 \%)$ than those earlier reported (Ezekiel et al., 2011; Tesfaw et al., 2013; Jasil et al., 2016) in which about $50 \%$ of the isolates tested exhibited multidrug resistance, suggesting the existence of higher frequency of MDR species in our study area. Multiple antibiotic resistance (MAR) among bacterial isolates from the various study locations is frightening because such organisms can become endemic within the environment and pose serious public health threats. Bacterial antibiotic resistance is transferable. If the resistant bacteria are allowed to distribute in the environment, they will most likely transfer resistance gene to other bacteria of same species or different. Dissemination of these resistant bacteria will not be restricted to a particular geographical area; drug resistance can be expected to spread steadily to all parts of the world. The scenario is plausible, but the risks cannot be estimated because of the insufficient understanding and of limited data availability. The isolation of antibiotic resistant bacteria in waste dump samples therefore is of public health concern because of the possibility of transferring multiple antibiotic resistances to the microbial flora and a potential for development of resistance in these microorganisms. They may also act as reservoirs which will contribute to the maintenance and spread of antibiotic resistance genes (Guardabassi et al., 2004). Many of the Salmonella spp. isolates from this study were observed to have patterns of resistance that indicate that the genes responsible were acquired from other organisms, such as resistances to antibiotics of different classes, and resistance that show that they produce extended spectrum beta-lactamases. Multidrug resistance (MDR) is a cause for concern in both clinical and veterinary medicine because it limits the therapeutic options available for treatment. Multiple antibiotic resistance (MAR) index is a measure of the extent of the isolates' resistance to antimicrobial agents within the group of antibiotics studied. According to Mishra et al. (2013), MAR index of 0.2 and above indicates high risk sources of contamination, MAR index of 0.4 and above is associated with human faecal source of contamination. Thenmozhi et al. (2014) opined that MAR index values $>0.2$ indicate existence of isolate from high risk contaminated source with frequent use of antibiotics while values $\leq 0.2$ show bacteria from source with less antibiotic usage. High MAR indices calls for vigilant surveillance and remedial measures. MAR index of 0.2 and above by $76 \%$ of Salmonella spp. isolates in this study is worrisome. Sensitivity patterns and treatment must be guided by laboratory investigations.

Conclusion: Results from this study showed that all parts of Zaria Metropolis were generally poor in sanitation and waste management and were reservoirs of antibiotic resistance. It is therefore advisable that, wastes should be removed regularly and the waste stream effectively managed. Persistent multiple drug resistance of most isolates to appropriate drugs of choice are of great public health concern and calls for periodic monitoring of antibiograms to detect possible changing patterns.

\section{REFERENCES}

Adekanle, MA; Oluremi, AS; Akindele, AA (2014). Bacteria isolated from waste dump sites soil at Osogbo, Osun State. J. Microbiol. Biotechnol. Res. 4(3): 66-69.

Ash, RJ; Mauck, B; Morgan, M (2002). “Antibiotic Resistance of Gram Negative Bacteria in Rivers, United States of America', Emerg. Inf. Dis. 8, 712.

Awisan, J; Venchito, DJ; Angelica, B; Lizlotte, C; Deanna, MF (2011). Aerobic Pathogenic and Opportunistic Bacteria of Public Health Significance in Ireland Dumpsites Soil',. SLU Res. J. 42(1): $27-$ 37.

Boyen, F; Haesebrouck, F; Maes, D; Van, I (2008). Nontyphoidal Salmonella Infections in Pigs: A Closer Look at Epidemiology, Pathogenesis and Control. Vet. Microbiol. 130: 1-19. 
Cheesbrough, M (2006). District Laboratory Practice in Tropical Countries, Part 1, 2ed. Cambridge, UK: Cambridge University Press. Pp 97-115.

Chigor, VN; Umoh, VJ; Smith, SI; Igbinosa, EO; Okoh, AI (2010). Multidrug Resistance and Plasmid Patterns of Escherichia coli O157:H7 and Other E. coli Isolatedfrom Diarrhoeal Stools and Surface Water from Some Selected Sources in Zaria, Nigeria'. Int. J. Environ. Res. Pub. 7, 3831-3841.

Clinical and Laboratory Standards Institute (2014), "Performance Standards for Antimicrobial Susceptibility Testing', Twenty-fourth info. Suppl. 28(1): $24-74$

Duru, EE; Agbagwa, OE; Umoren, FE (2014). Bacterial Agents Associated with Infantile Diarrhea and Their Antibiotics Susceptibility Pattern in Port Harcourt, South-South Nigeria. J. Med. Sci. Pub. 3(1): 1-12.

Ezekiel, CN; Olarimmoye, AO; Oyinloye, INA; Olaoye, OB; Edum, AO (2011). Distribution, Antibiogram and Multidrug Resistance in Enterobacteriaceae from Commercial Poultry Feeds in Nigeria'. Afr. J. Microbiol. Res. 5(3): 294-301.

Gregory, D; Keah-ying, L; Sunny, CJ (2013). "Quantitative Microbial Risk Assessment of Pathogenic Vibrios in Marine Recreational Waters of Southern California'. Appl. Environ. Microbiol. 79(1): 294-302.

Guardabassi, L Schwarz, S; Lloyd, DH (2004). "Pet Animals as Reservoirs of Antimicrobial Resistance', J. Ant. Chemother. 54, 321- 332.

Ikpeme, E; Nfongeh, J; Enyi-Idoh, K; Eja, ME; Etim, L (2011). "Antibiotic Susceptibility Profiles of Enteric Bacterial Isolates from Dumpsite Utisols and Water Sources in a Rural Community in Cross River State, Southern Nigeria', Nat. Sci. 9(5): 46.

Isirima, MO; Braide, SA; Chindah, AC; Nwachukwu, D; Ikoro, UJ;Osuamkpe, A; Igwe, C (2005).

"Technical Reports: Institute of Pollution Studies Laboratory', Rivers State University of Science and Technology, Port Harcourt.

Liu, YN; Wang, Y; Walsh, TR; Yi, LX; Zhang, RS (2016). "Emergence of Plasmid Mediated Colistin Resistance MCR-I in Animals and Human Beings in China: A Microbiological and Molecular Biology Study'. Lanc. Inf. Dis.16, 161-168.

Nazzal, Z; Said, H; Al-Hajiri, M; Tamim, O (2012). Salmonella food poisoning associated with macroni salad in a labourer's camp state of Qatar, 2010. J.Com. Med. Edu. 2: 145.

Nyandjou, YMC; Yakubu, SE; Abdullahi, IO; Machido, DA (2017). Screening for Multidrug Resistant Escherichia coli O157:H7 Isolated from Refuse Dumpsites in Zaria Metropolis, Nigeria. Nig. J. Sci. Res. 16(3): 276-281.

Odeyemi, AT (2012). Antibiogram Status of Bacterial Isolates from Air Around Dump Site of Ekiti State Destitute Centre at Ilokun, Ado-Ekiti, Nigeria', $J$. Microbiol. Res. 2(2):12-18

Okeke, I.N; Sosa, A (2003). Antibiotic Resistance in Africa- Discerning the Enemy and Plotting a Defense. Published by APUA, USA, Pp. 1 -19.

Olatoye, IO (2010). "Incidence and Antibiotics Susceptibility of Escherichia coli 0157:H7 from Beef in Ibadan Municipal, Nigeria', Afr. J. Biotechnol. 9(8): 1196-1199.

Sharma, BC; Rai, B (2012). Incidence of multidrug resistance in Escherichia coli strains isolated from three lakes of Tourist attraction (Mirik lake), Jorepokhari lake and Nakhapani lake) of Darjeeling hills, India. Ind. J. Fund. Appl. Sci. 2(2):108-114.

Tesfaw, L.B; Taye, S; Alemu, H; Alemayehu, ZS; Negussle, H (2013). Prevalence and Antimicrobial Resistance Profile of Salmonella Isolated from Dairy Products in Addis Ababa, Ethiopia. Aca. J. 7(43): 5046-5050.

Thenmozhi, S; Rajeswari, P; Suresh, KT; Saipriyanga, V; Kalpana, M (2014). Multi-drug Resistant Patterns of Biofilm Forming Aeromonas hydrophila from Urine Samples. Int. J. Pharm. Sci. Res. 5(7): 2908-2918.

Uba, S; Zairu, A; Sallau, MS; Abba, H; Okunola, OJ (2013). Metals Bioavailability in the Leachates from Dumpsites in Zaria Metropolis, Nigeria. J. Tox. Environ. Sci. 5 (7): 131141.

World Health Organization (2011). Managing Zoonotic Public Health Risks at the Human-AnimalEcosystem Interface. www.who.int/zoonoses/en

World Health Organization (2011). Antimicrobial Resistance: Global Report on Surveillance. Geneva, Switzerland: WHO Press. 